Gut, 1985, 26, 158-163

\title{
Long term prognosis in ulcerative colitis - based on results from a regional patient group from the county of Copenhagen
}

\author{
C HENDRIKSEN, S KREINER, AND V BINDER \\ From the Medical-Gastroenterological Department C, Herlev Hospital, University of Copenhagen, Denmark
}

SUMmaRY The prognosis of ulcerative colitis including survival, colectomy rate, activity of disease, and working capacity was estimated from a follow up study of 783 patients with ulcerative colitis comprising all patients from the county of Copenhagen, except for the island of Amager, diagnosed between 1960 and 1978. The period of observation ranged from one to 18 years with a median of 6.7 years for the clinical observations, eight years for survival and 11.6 years for the occurrence of large bowel cancer. The follow up was $100 \%$ for both survival and cancer. The survival rate in women did not differ from that in the general population. In men over 40 years of age at diagnosis a slight excess mortality was found, but only in the year of diagnosis $(2 \cdot 1 \%)$ and the following year $(1 \cdot 5 \%)$. Colonic cancer was seen in only seven out of the 783 patients, corresponding to an annual risk of $0.07 \%$ and a cumulative risk after 18 years with ulcerative colitis of $1.4 \%$ (95\% confidence limits, $0.7-2 \cdot 8 \%$ ) independent of the initial extent of disease. The colectomy rate was $9.6 \%$ in the year of diagnosis. The cumulative 10 - and 18-year colectomy rate was $23 \%$ and $31 \%$, respectively. After three years from diagnosis the capacity for work both in those subject to resection and treated conservatively did not differ significantly from that in the background population. At any time about $50 \%$ of the patients were without symptoms, in about $30 \%$ the disease activity was low and in about $20 \%$ moderate or high. Most patients, however, differed in activity from one year to another and almost all patients $(97 \%)$ experienced at least one relapse during a 10 year time period.

The impact of a chronic disease on the life of the individual depends on three major factors: the premorbid state of the patient (age, intellectual condition, physical condition, etc), the course of the disease (intermittent or continuous, high or moderate activity, etc), and the efficacy and type of treatment. These factors combined determine the prognosis of the disease in terms of survival as well as in measurement of the quality of life.

The aim of the present study was to evaluate the prognosis of ulcerative colitis on the basis of survival, working capacity, colectomy rate, activity and course of disease, and thereby attempt to answer the inevitable question from the newly diagnosed patient: 'How will the disease influence my life in the future?'

Address for correspondence: V Binder, Medical Department C, Herlev Hospital, DK-2730 Herlev, Denmark.

Received for publication 9 May 1984
Long term follow up studies of all cases within a sufficiently large region are a prerequisite for the study of the prognosis of a specific chronic disease.

All patients with ulcerative colitis in the county of Copenhagen have been followed regularly since 1960. The results form the basis of the present work.

\section{Methods}

\section{PATIENTS}

BACKGROUND POPULATION

The background area was the county of Copenhagen except for a small part on the Island of Amager. The region comprises the outskirts of central Copenhagen with a population of 433043 in 1960 and 573237 in 1978 - more than $10 \%$ of the total Danish population.

The national health system provides free medical care including sick day pay. Thus, no patient has to abstain from treatment for economic reasons. 
STUDY POPULATION

In total 783 patients, 342 men and 441 women, who were residents of the county of Copenhagen, fulfilled the diagnostic criteria of ulcerative colitis during the period 1960-1978. The diagnostic criteria and a detailed description of the patients have been published. $^{12}$ The median age at diagnosis was 33.0 years for men and 34.4 years for women.

Among the patients, $78 \%$ were diagnosed and treated in our department, and the remaining $22 \%$ attended other hospitals within the area. The principles of diagnosis and treatment were the same, and all clinical data have been made available for the study.

One hundred and twenty four patients $(16 \%)$ had total colon involvement, $319(41 \%)$ extending beyond the rectum and $318(41 \%)$ only rectal involvement judged radiologically, at the time of diagnosis.

\section{CLINICAL FOLLOW UP}

The patients were reviewed annually or more frequently if symptomatic. An annual assessment was made as to inflammatory activity, working capacity, treatment, and the cancer risk considered.

The principles of treatment have been similar throughout the study period as previously described: ${ }^{3}$ long-term sulphasalazine to prevent relapses; prednisolone locally and/or systemically in short time courses during flare up periods; colectomy in case of failure of medical treatment, including short lasting, intense steroid treatment. Colectomy was also performed in case of a long standing chronic disease requiring frequent or continuous steroid treatment. Colectomy has not been performed as cancer prophylaxis.

The patients were followed from the time of diagnosis until 31 December 1978 or until death (67 patients), emigration from the district (92 patients), or termination of follow up by the patient for other personal reasons (106 patients). One hundred and eighty-eight patients $(24 \%)$ were followed for 11 years or more, 42 patients $(5 \%)$ for more than 15 years. At the end of the study 512 patients were still under review. The follow up period ranged from one to 18 years (mean 6.7 years).

Through the Danish Central Person Register the patients who dropped out during the study were traced as regards survival at the end of the study period, so that all deaths are included in the present survival curves, the median observation period being 8.0 years (mean 7.9 years). Through the Danish Cancer Registry the total group of ulcerative colitis patients was traced until the end of 1982 as regards occurrence of gastrointestinal cancer, yielding a median observation period for this specific variable of 11.6 years (mean 11.6 years).

\section{DEFINITIONS}

Each observation year has been classified according to the following criteria.

\section{COURSE OF DISEASE}

Intermittent: occurrence of symptom-free period(s) of at least one month's duration excluding periods where the patient was in steroid treatment. Continuous: without symptom-free periods. Inactive: completely free of bowel symptoms during the year. Low activity: more than two and not more than four bowel movements per day and/or less than daily occurrence of blood/pus in the stools. No general symptoms such as fever or loss of weight. High activity: more than four bowel movements per day and/or daily occurrence of blood/pus in the stools with or without general symptoms such as fever or loss of weight.

\section{CAPACITY FOR WORK}

The capacity for work was defined by the days lost through sickness, independent of cause. Fully capable: less than one month lost through sickness during the year. Partly capable: one month or more but less than 11 months lost through sickness during the year. Not capable: 11 months or more lost through sickness during the year.

\section{STATISTICAL METHODS}

The risk of death was finally compared with the mortality of the population at large. For each year after diagnosis, the expected number of deaths among the patients at risk was estimated taking into account for each individual both sex, age, and calendar year. The difference between the observed and the expected number of deaths was evaluated on the assumption that the actual number of deaths is distributed according to a Poisson distribution.

\section{Results}

SURVIVAL RATES

Patients with ulcerative colitis are shown in Figs. 1 and 2 together with their survival rates of the age-matched background population. In the women the survival did not differ between the patients and the background population at any time. The men had a slightly increased mortality in the year of diagnosis $(2.1 \%)$ and the following year $(1.5 \%)$. From the second year after diagnosis the survival did not differ from that of the background population. The extra mortality in the first and the second disease year was only significant in age groups over 40 years at diagnosis. 


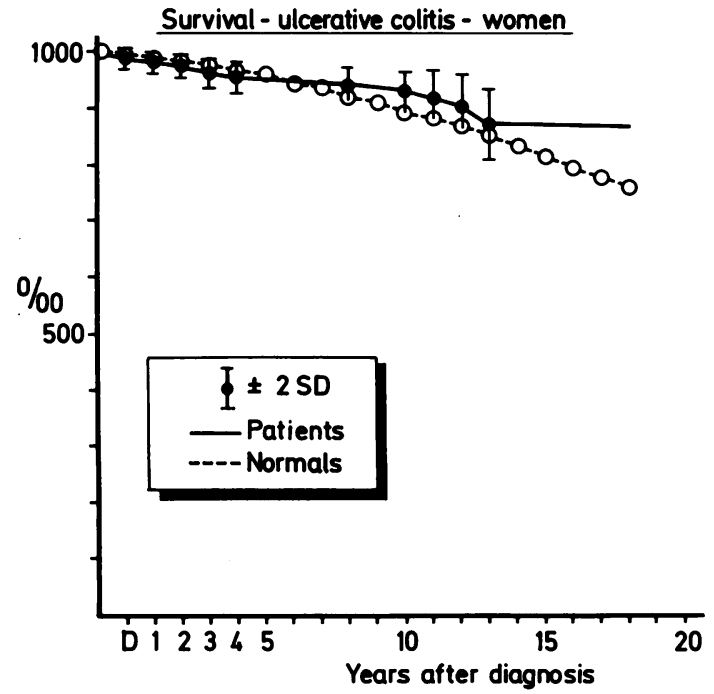

Fig. 1 Survival of women with ulcerative colitis compared with the age-and sex-matched background population.

\section{RISK OF CANCER}

This was found to be very low. Only seven of the 783 patients developed colonic cancer during the observation period, and the additional four years from 1979 to the end of 1982 . This compares with an annual risk of $0.077 \% \quad(95 \%$ confidence limits, $0 \cdot 037-0 \cdot 159 \%)$. The cumulative risk of developing colonic cancer at 10 years is $0.8 \%$, at 15 years $1.1 \%$,

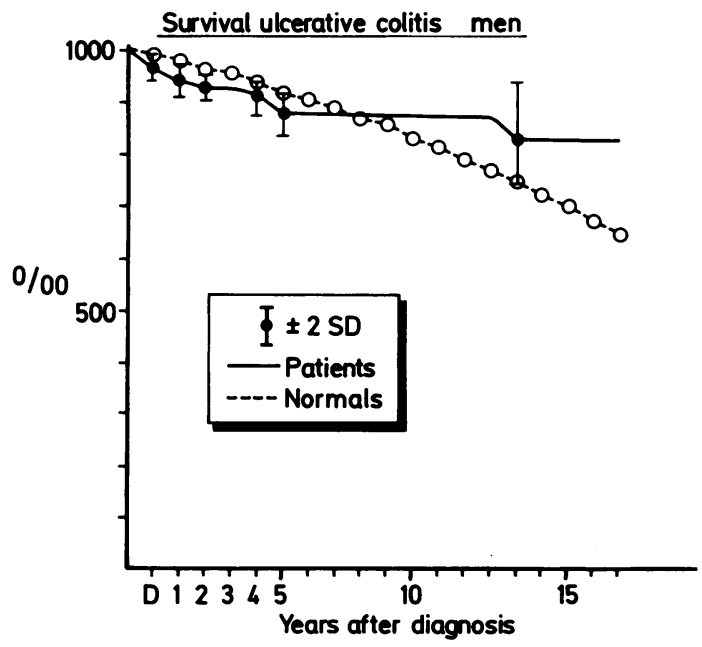

Fig. 2 Survival of men with ulcerative colitis compared with the age-and sex-matched background population. and at 18 years $1.4 \%$ with $95 \%$ confidence limits, $0 \cdot 7-2 \cdot 8 \%$. The seven cases of cancer are described in details in Table 1 . The cumulative risk of developing cancer was not influenced by the initial extent of the colitis. The cumulative risk after 18 years was $1.3 \%$ for patients with total colon involvement at the time of diagnosis.

COLECTOMY RATE

This was estimated for each year after diagnosis (Fig. 3). Ten per cent of the patients had an operation in the year of diagnosis and 3\% in the following year. After four years the risk of undergoing colectomy was constant, about $1 \%$ per year. In Figure 4 the cumulative colectomy rates are given. A total of 149 patients underwent colectomy during the observation period.

\section{ACTIVITY OF DISEASE}

This was estimated for each separate year after diagnosis (Fig. 5). At any time about $50 \%$ of the patients were free of symptoms. The percentage was increased slightly with increasing duration of the disease. Similarly, in about $30 \%$ the disease was at any time in low activity and in about $20 \%$ in moderate or high activity. Most patients, however, differ in activity from one year to another. The chance of being free of relapses is seen in Figure 6 . After 10 years less than $3 \%$ and after 18 years less than $1 \%$ of the patients had not experienced a relapse.

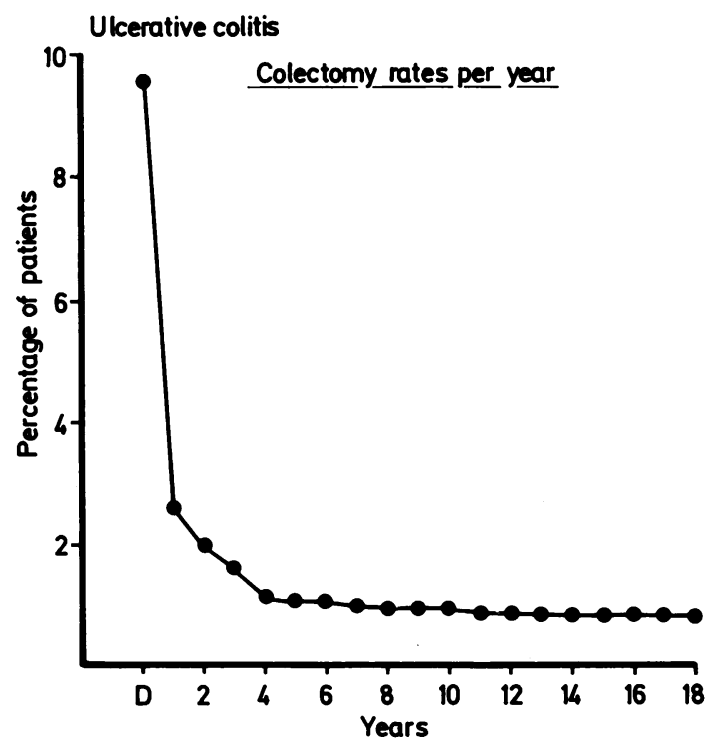

Fig. 3 Colectomy rates in different years after the diagnosis of ulcerative colitis. 
Table 1 Seven cases of colonic cancer among 783 patients with ulcerative colitis

\begin{tabular}{lllllll}
\hline & Sex & $\begin{array}{l}\text { Age at cancer } \\
\text { diagnosis }(y r)\end{array}$ & $\begin{array}{l}\text { Duration from IBD } \\
\text { diagnosis }(y r)\end{array}$ & $\begin{array}{l}\text { Duration from first } \\
\text { IBD symptom }(y r)\end{array}$ & $\begin{array}{l}\text { Extent of colitis at } \\
\text { IBD diagnosis }\end{array}$ & $\begin{array}{l}\text { Localisation of } \\
\text { cancer }\end{array}$ \\
\hline NS & M & 41 & 24 & 24 & Substantial part & Caecum \\
KW & F & 74 & 44 & 58 & All colon & Rectum \\
BH & M & 15 & 4 & 12 & All colon & Sigmoid \\
VO & M & 69 & 19 & 19 & Substantial part & Rectum \\
BF & M & 73 & 13 & 56 & Rectum only & Caecum \\
LN & F & 40 & 4 & 9 & Substantial part & Ascendens \\
MH & F & 32 & 17 & 18 & Substantial part & Rectum \\
\hline
\end{tabular}

\section{COURSE OF DISEASE}

This was defined as continuous, intermittent, or inactive - as shown in Figure 7 for each year after diagnosis. About $10 \%$ of the patients had a continuous and about $40 \%$ an intermittent course. This calculation was based upon unoperated patients only, but included patient years up to the time of operation.

A continuous course over several years was rare, and the cumulative probability of such a course is shown in Table 2 . The percentage of patients with persistent symptoms fell rapidly during the first few years and was almost zero after 10 years because many of this group underwent colectomy.

\section{WORKING CAPACITY}

This was estimated for all patients in their employable age, shown in Figure 8, for each year after diagnosis. Except for the first few years, about $90 \%$ of the patients were fully capable of work. Less than $5 \%$ received disablement pension and practically none of them because of their inflammatory bowel disease.

\section{Discussion}

We have previously shown that our patient group

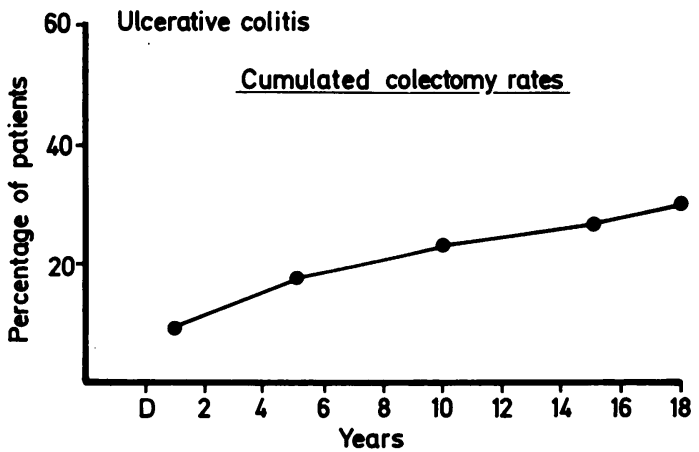

Fig. 4 Cumulative colectomy rates in the ulcerative colitis patients. comprises more than $99 \%$ of all patients in the region who have had the diagnosis of ulcerative colitis made. ${ }^{2}$ In 16 patients the initial diagnosis of ulcerative colitis appeared later to be Crohn's disease. In six patients the diagnosis was changed during the observation period from Crohn's disease to ulcerative colitis. The patients were included in the present study for all years during which they fulfilled the diagnostic criteria of ulcerative colitis.

The follow up was $100 \%$ concerning survival and cancer occurrence, since patients who emigrated from the area or dropped out for other reasons were traced at the end of the study via the Danish Central Person Register and Cancer Registry. Additionally the period 1979-1982 was included for cancer occurrence, thus increasing the median observation period to 11.6 years.

The clinical results were only obtainable for the years when they attended one of the clinics in the

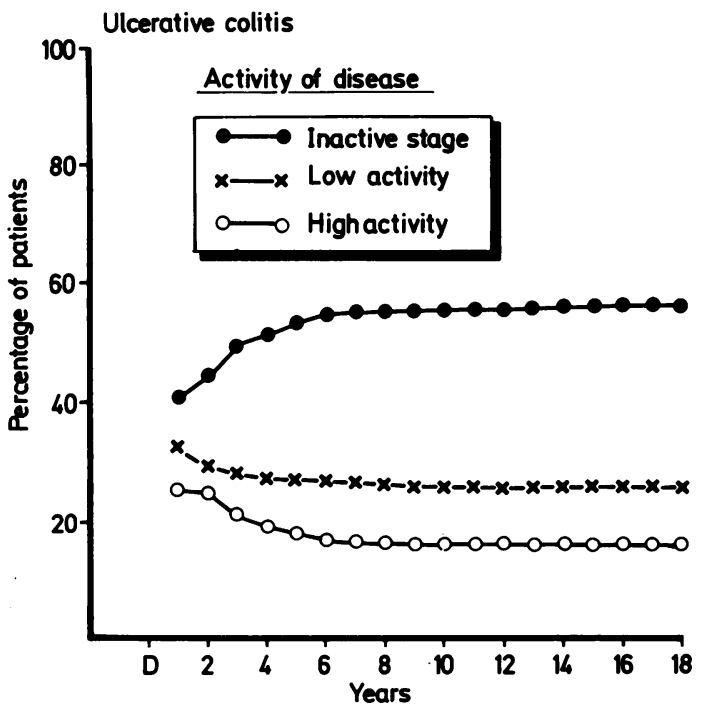

Fig. 5 Disease activity. Calculations based upon all patients who were alive and conservatively treated. 


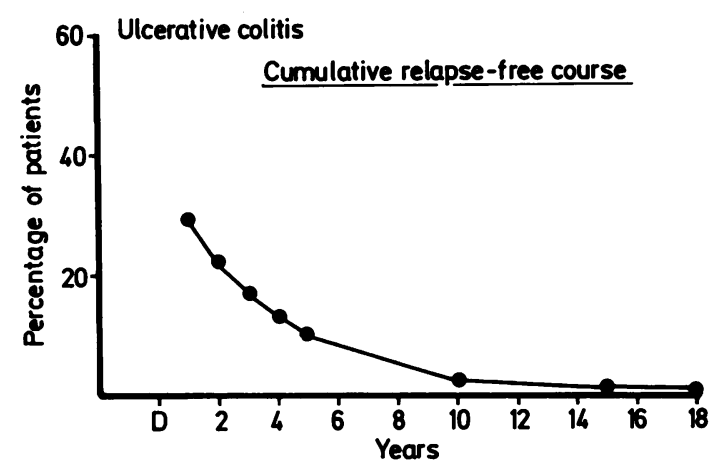

Fig. 6 Cumulative course of ulcerative colitis calculated on the basis of conservatively treated.

area. The analyses revealed a stationary course from the fifth year from diagnosis onwards. An analysis was made of the clinical disease activity and course of disease in the year before drop out for those patients who were lost because of emigration from the district or who failed to attend for personal reasons. The analysis showed no difference in the disease activity and course between these patients and those remaining in the study. Thus it seems that the remaining patient group was not skewed.

The excellent overall prognosis of ulcerative colitis in this study confirms results previously published from our group for the period 1960-1971, ${ }^{3}$ and our cancer risk figures are similar to those recorded from Israel. ${ }^{4}$ Other studies, ${ }^{5-10}$ however, have shown a more serious prognosis with a higher mortality and a higher cancer risk. The regional and thereby unselected patient group in our study tends to show the true picture of the disease and a better prognosis than in a group of patients selected for

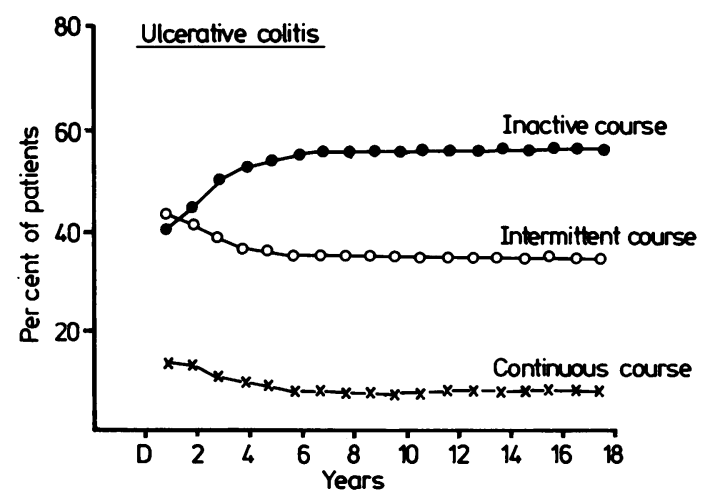

Fig. 7 Course of disease. Calculations based upon all patients who were alive and conservatively treated.
Table 2 Cumulative course of ulcerative colitis calculated on the basis of unoperated patients only

\begin{tabular}{ll}
\hline Duration of disease $(y r)$ & Continuous since start of disease (\%) \\
\hline 1 & $12 \cdot 6$ \\
2 & $5 \cdot 8$ \\
3 & $3 \cdot 2$ \\
4 & $1 \cdot 8$ \\
5 & $1 \cdot 0$ \\
10 & $0 \cdot 05$ \\
15 & $0 \cdot 003$ \\
18 & $0 \cdot 0$ \\
\hline
\end{tabular}

severity. Further patients in this study were treated by a specialist group from onset which presumably will lead to a better prognosis. The therapeutic approach has been active - that is, the patients have been controlled regularly in the outpatient clinic and with rapid admission to hospital in the case of relapse.

The possibility that ulcerative colitis may take a less serious course in Denmark seems unlikely, because about $30 \%$ of the patients underwent colectomy within the first 18 years. Among the patients treated by colectomy the largest part comprises patients with initial total colon involvement. Since it is known that patients with extensive colitis are at risk for cancer, our therapeutic policy in the first years after diagnosis has reduced the number of patients at risk.

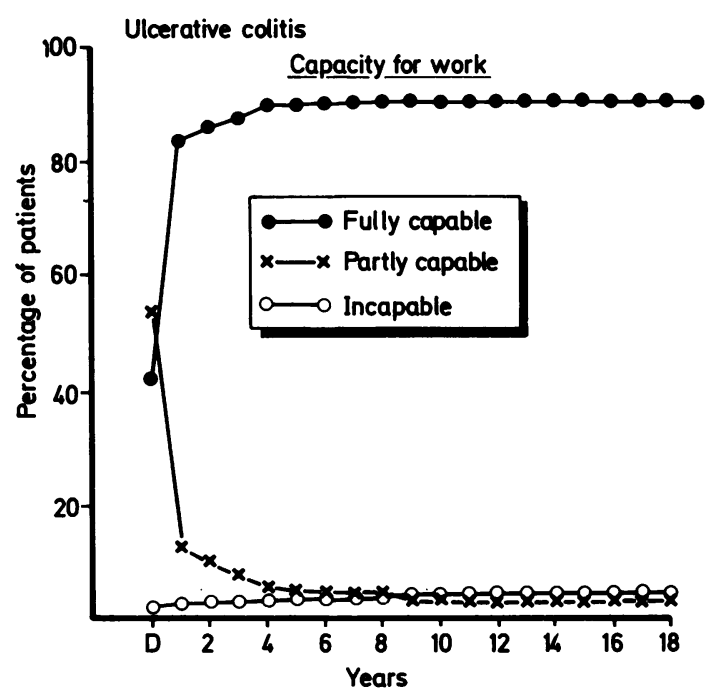

Fig. 8 Probability of being capable for work for each separate year. The calculations comprises all patients with ulcerative colitis both medically and surgically treated. 
As far as the course of disease, the present results are in good agreement with the findings from Leeds ${ }^{11}$ and London. ${ }^{12}$ The finding that $90 \%$ of the patients were fully capable for work is similar to that in the background population, even if a directly comparable registration of absence from work is not available. In $19814.4 \%$ of the Danish population between 14 and 66 years received disablement pension, ${ }^{13}$ a figure which does not differ from that found in our ulcerative colitis patients. These results on social prognosis are in agreement with a previous study which compared a randomised group of ulcerative colitis patients with an age- and sexmatched control group. ${ }^{14}$ The two groups were similar in marital status, the frequency of severe family or sexual problems, leisure activities, physical capacity and earning capacity, the incidence of mental disorders, and intake of alcohol and psychopharmacological drugs.

A very recent study from Scotland ${ }^{15}$ showed a good prognosis in ulcerative colitis as in the present study with an improving course as the duration of the disease increased. The reported incidence of ulcerative colitis in Scotland is much higher than our own study.

Ulcerative colitis has a chronic course, and the inconveniences for operated as well as unoperated patients should not be minimised. It however, appears that with an active therapeutic approach the patients seem to lead a near normal life.

This work was supported by the Danish Medical Research Council (Grant No. 12-9080).

\section{References}

1 Both H, Torp-Pedersen K, Kreiner S, Hendriksen C, Binder V. Clinical appearance at diagnosis of ulcerative colitis and Crohn's disease in a regional patient group. Scand J Gastroenterol 1983; 18: 987-91.

2 Binder V, Both H, Hansen PK, Hendriksen C, Kreiner $\mathrm{S}$, Torp-Pedersen $\mathrm{K}$. Incidence and prevalence of ulcerative colitis and Crohn's disease in the County of Copenhagen, 1962 to 1978. Gastroenterology 1982; 83: 563-8.

3 Bonnevie O, Binder V, Anthonisen P, Riis P. The prognosis of ulcerative colitis. Scand J Gastroenterol 1974; 9: 81-91.

4 Gilat T, Zemishlany Z, Ribak J et al. Ulcerative colitis in the Jewish population of Tel-Aviv Yafo. II: The racity of malignant degeneration. Gastroenterology 1974; 67: 933-8.

5 Jalan KN, Prescott RJ, Sircus W et al. An experience of ulcerative colitis. III. Long term outcome. Gastroenterology 1970; 59: 598-609.

6 Lennard-Jones JE, Misiewicz JJ, Parrish JA et al. Prospective study of outpatients with extensive colitis. Lancet 1974; 1: 1065-7.

7 Storgaard L, Bischoff N, Henriksen FW et al. Survival rate in Crohn's disease and ulcerative colitis. Scand J Gastroenterol 1979; 14: 225-30.

8 Lanfranchi GA, Brignola C, Michelini M et al. Clinical course of ulcerative colitis in Italy. Digestion 1980; 20: 106-10.

9 Gyde S, Prior P, Dew MJ et al. Mortality in ulcerative colitis. Gastroenterology 1982; 83: 36-43.

10 Gilat T, Lilos P, Zemishlany Z, Ribak J, Benaroya Y. Ulcerative colitis in the Jewish population of Tel-Aviv Yafo. III: Clinical course. Gastroenterology 1976; 70: 14-9.

11 Watts JMcK, de Dombal FT, Watkinson G, Goligher JC. Long-term prognosis of ulcerative colitis. $\mathrm{Br} \mathrm{Med} \mathrm{J}$ 1966; 1: 1447-53.

12 Ritchie JK, Powell-Tuck J, Lennard-Jones JE. Clinical outcome of the first ten years of ulcerative colitis and proctitis. Lancet 1978; 1: 1140-3.

13 Statistiske efterretninger A28. Danmarks Statistik (Denmark's Central Statistical Agency), 1981.

14 Hendriksen C, Binder V. Social prognosis in patients with ulcerative colitis. $\mathrm{Br}$ Med J 1980; 281: 581-3.

15 Sinclair TS, Brunt PW, Mowat NAG. Nonspecific proctocolitis in Northeastern Scotland: a community study. Gastroenterology 1983; 85: 1-11. 